\title{
Analysis of Unsteady-State Temperature Distribution in Python Based Joglo Building
}

\author{
Raihan Hendraji ${ }^{1,2}$, Viska Noviantri ${ }^{3}$, Irene Anindaputri Iswanto ${ }^{1}$ \\ ${ }^{1}$ Computer Science Department, School of Computer Science, Bina Nusantara University, Jakarta, Indonesia \\ 11480 \\ ${ }^{2}$ Mathematics Department, School of Computer Science, Bina Nusantara University, Jakarta, Indonesia 11480 \\ ${ }^{3}$ Mathematics Department, School of Computer Science, Bina Nusantara University, Jakarta, Indonesia 11480, \\ viskanoviantri@binus.ac.id
}

\begin{abstract}
The shape of the roof of a building affects the temperature distribution of the building, if the shape of the roof of the building changes, the temperature distribution also changes. Joglo-roofed buildings are still very popular in Indonesia, especially for the people of Central Java. Joglo roof is a roof that has two different slope angles, and has a partner on the other side of the mirror. The angle in the meeting of two roofs on the same side must be greater than $180 \mathrm{O}$. Unsteadystate heat equations can represent temperature distribution in joglo-roofed buildings. Using a finite difference scheme with the ghost point method that is solved numerically and uses the Quadratic Extrapolation approach, unsteady-state heat equations can be solved. The results of this simulation aim to be a reference that can be used by construction industry workers in the construction of buildings that have a joglo roof. This research results in the fact that the longer the time given, the high temperature value will decrease by itself due to heat distribution.
\end{abstract}

Key words : Ghost Point Method, Quadratic Extrapolation, Temperature Distribution of joglo-roofed building, Unsteady State Heat Equation.

\section{INTRODUCTION}

Today, global warming is one of the problems that has taken the attention of the wider community. Global warming is a process of increasing the average temperature of the atmosphere, ocean, and earth's landmass. Data from National Geographic confirmed by NASA (National Aeronautics and Space Administration), NOAA (National Oceanic and Atmospheric Administration), and Japan Meteorological Agency show that the average temperature on the surface of the earth has increased by $1.26 \square$ from the 1880 s until June 2015.

Temperature is a physical quantity that states the degree of heat of a substance. The temperature has many units used by society, for example, Celsius, Kelvin, Fahrenheit, and Reaumur. The use of temperature and its units used in people's lives, which measures the degree of heat of a room. The space that is usually measured by the degree of heat is the room, food cooler, water heater, etc.

Space, where ordinary people carry out their activities, has its temperature. Comfortable room temperature is at $20 \square$ (Celsius) - $26 \square$ (Celsius) [1]. As a result of global warming, one of them is the increase in the average temperature of the earth's surface, which causes an increase in the heat of the existing space on earth. Humans will lose the feeling of comfort when in a room where the temperature exceeds the comfortable limit. Meanwhile, satisfaction is an essential thing if someone wants to rest or do work or other items.

The house is a basic human need as a place of shelter and rest. A decent home has three aspects: floor, wall, and roof. The roof is one part of the house that protects the occupants from direct temperature transfer both hot and cold. The roof has various forms, for example, flat and standard (triangular) to joglo-shaped. Whatever the shape, the roof must be able to withstand the transfer of temperature directly from and into the room. Besides, the roof also able to flow from the ceiling above the water down when rain or snow occurs.

Data from the Central Statistics Agency in the study of Population Growth and Distribution of Indonesian Population Results of the 2010 Population Census conveyed that $57 \%$ of Indonesian people centered on Java. Many people who live on the island of Java still live at home in a traditional form. The conventional style of the island in Java is mostly with a joglo roof. People choose a traditional house with a joglo roof because of the level of comfort.

Research on thermal comfort in buildings with several forms of roofing, including the type of a joglo roof has been conducted by (Purwanto, Hermawan, Ridwan, 2012). In this study, the authors describe the temperature distribution for several traditional houses through direct measurement with a digital thermometer. This study also discusses thermal comfort factors that are influenced by human activities in the home.

Research on the temperature distribution of a room with a different roof shape has been done by [2]. One of them is the shape of the joglo roof. In this study, the authors used the 
Raihan Hendraji et al., International Journal of Emerging Trends in Engineering Research, 8(9), September 2020, $5788-5793$

finite difference and finite element methods in steady-state. The results of his research showed that in a steady-state, the standard shaped roof (triangular) and the shape of the joglo roof were not as good as the arched roof (dome roof) in reducing the heat entering the building. This study also made mathematical modeling to find out how much heat entered the structure of the house.

The making of temperature distribution simulation applications on buildings with different roof shapes has been made by [3]. In the form the user is asked to enter the length of the building, the height of the building, the slope of the roof, and the initial temperature of the roof, floor, right and left sidewalls of the house to be simulated. But the shape of the joglo roof cannot be calculated by the application because in the form can only enter one angle of the roof slope while in the joglo house has two different roof slope angles. The app also uses only numeric input that cannot describe the form entered by the application user.

Referring to some of the problems and research previously explained, the author decided to make a study entitled Analysis of Unsteady-State Temperature Distribution in a Joglo-Based Building in Python. Where the author will raise the topic of fluid dynamics with some development, research, and the making of previous applications. The author will only focus on the joglo-shaped roof because joglo-roofed houses are still widely used by Indonesian people. Additionally, joglo-roofed dwellings do not have apps that can visualize the temperature distribution in the room. Therefore, the authors will create a heat distribution simulation application based on the results of data calculations that have been provided by the application user. Mathematical modeling will be represented through the Unsteady State heat equation so that it will produce a visualization of the temperature distribution that changes (a steady-state). The method to be used in this research is the Finite Difference Method with the assistance of the Ghost Point method through the Quadratic Extrapolation approach, which will be used in solving the heat equation.

\subsection{Theoretical Basis}

A ghost point method is a numerical approach that is used to solve a problem in a domain or boundary test that is irregular or arbitrary. Problems that can be solved using ghost points are problems that cannot be solved using finite difference methods [4]. Any free or restricted testing domain has a way to solve the problem. Although using the same scheme that is a finite difference, any random field will use a point outside the area to calculate the point value in that domain.

In the process of finding the value of the dark blue point, four types of ghost point extrapolation approach used. Namely, Constant Extrapolation, Linear Extrapolation, Quadratic Extrapolation, and Cubic Extrapolation. Following is an explanation of each of the extrapolation approaches:

1. Constant Extrapolation

$$
\tilde{\mathrm{U}}(\mathrm{x})=\mathrm{U}_{\mathrm{i}}
$$

Constant

Extrapolation

conclude that the whole ghost point $\tilde{U}(\mathrm{x})$ outside the test, the domain has the same value as the point $\mathrm{U}_{\mathrm{i}}$ which is right within the limits of the test domain (boundary).

\section{Linear Extrapolation}

$$
\tilde{\mathrm{U}}(\mathrm{x})=\mathrm{ax}+\mathrm{b}
$$

To find the coefficients $a$ and $b$ which will be used to find ghost points $\tilde{\mathrm{U}}(\mathrm{x})$, used the equation system as follows:

$$
\tilde{\mathrm{U}}(0)=\mathrm{U}_{\mathrm{i}}, \quad \tilde{\mathrm{U}}\left(\mathrm{x}_{\mathrm{i}}-\mathrm{x}_{1}\right)=\mathrm{U}_{1}
$$

3. Quadratic Extrapolation

$$
\begin{array}{ll}
\mathrm{T} & \tilde{\mathrm{U}}(\mathrm{x})=\mathrm{ax}^{2}+\mathrm{bx}+\mathrm{c} \\
\mathrm{o} & \\
\mathrm{fi} &
\end{array}
$$

nd the coefficient $a, \mathrm{~b}$ and $\mathrm{c}$ which will be used to find ghost points $\tilde{U}(\mathrm{x})$, used the equation system as follows:

$$
\begin{gathered}
\tilde{\mathrm{U}}(0)=\mathrm{U}_{\mathrm{i}}, \quad \tilde{\mathrm{U}}(-\Delta \mathrm{x})=\mathrm{U}_{\mathrm{i}-1}, \quad \tilde{\mathrm{U}}\left(\mathrm{x}_{\mathrm{i}}-\mathrm{x}_{1}\right) \\
=\mathrm{U}_{1}
\end{gathered}
$$

4. Cubic Extrapolation

$$
\tilde{\mathrm{U}}(\mathrm{x})=a \mathrm{x}^{3}+\mathrm{bx}^{2}+\mathrm{cx}+\mathrm{d}
$$

To find the coefficient $a, \mathrm{~b}, \mathrm{c}$ and $\mathrm{d}$ which will be used to find ghost points $\tilde{\mathrm{U}}(\mathrm{x})$, used the equation system as follows:

$$
\begin{gathered}
\tilde{\mathrm{U}}(0)=\mathrm{U}_{\mathrm{i}}, \tilde{\mathrm{U}}(-\Delta \mathrm{x})=\mathrm{U}_{\mathrm{i}-1}, \tilde{\mathrm{U}}(-2 \Delta \mathrm{x})=\mathrm{U}_{\mathrm{i}-2}, \\
\tilde{\mathrm{U}}\left(\mathrm{x}_{\mathrm{i}}-\mathrm{x}_{1}\right)=\mathrm{U}_{1}
\end{gathered}
$$

The extrapolation approach method that will be used in this research is the quadratic extrapolation method whose form of the equation is $\tilde{U}(\mathrm{x})=a \mathrm{x}^{2}+\mathrm{bx}+\mathrm{c}$. Afterwards, the obtained number from Ũ $(\mathrm{x})$ will be used to replace the ghost point value that is affected by the different schemes used.

According to [5], python is a high-level programming language that is interpreted, interactive, and object-oriented that can operate on almost all operating system platforms such as Linux, Unix, Windows, Mac OS, and others.

Python is an object-oriented programming language developed in the late 1980s as a scripting language. The code in python is not compiled and run into machine language, but rather it is run using an interpreter. Interpreters operate by reading code from the application line by line and processing it, causing interpreters to need faster time to run a code compared to having to read the entire code first to be able to run [5].

Some of the advantages of the Python programming language compared to other programming languages [6]are:

1. Python is software that is open-source, which means it's free and free to use by all users.

2. Python can be run almost on all operating system platforms such as Linux, Unix, Windows, Mac OS, and others.

3. Python is easier to learn and has more code to read and understand.

4. Python and its extensions are easy to install.

5. Python has many standard libraries that can be used. 
In the process of compiling the program, some libraries in python that are used are as follows:

1. NumPy

NumPy is a python module or library that is used to run computerized processes related to scientific computing. Numpy can be used to form arrays that can hold multidimensional data so that it can simplify the computerization process that will be performed.

\section{Math}

Math is a python module or library that defines various mathematical functions to make it easier to use during the programming process.

3. Matplotlib

Matplotlib is a python module or library that is used to make two-dimensional or three-dimensional plots of existing data. The plot results displayed are in the form of distribution of points, line charts, bar charts, histograms, spectra, temperature contours, and others.

4. TkInter

TkInter is a python module or library that is used to create a user interface for a program. TkInter is a default module for Microsoft Windows and macOS X in python installations.

\section{RESEARCH METHODOLOGY}

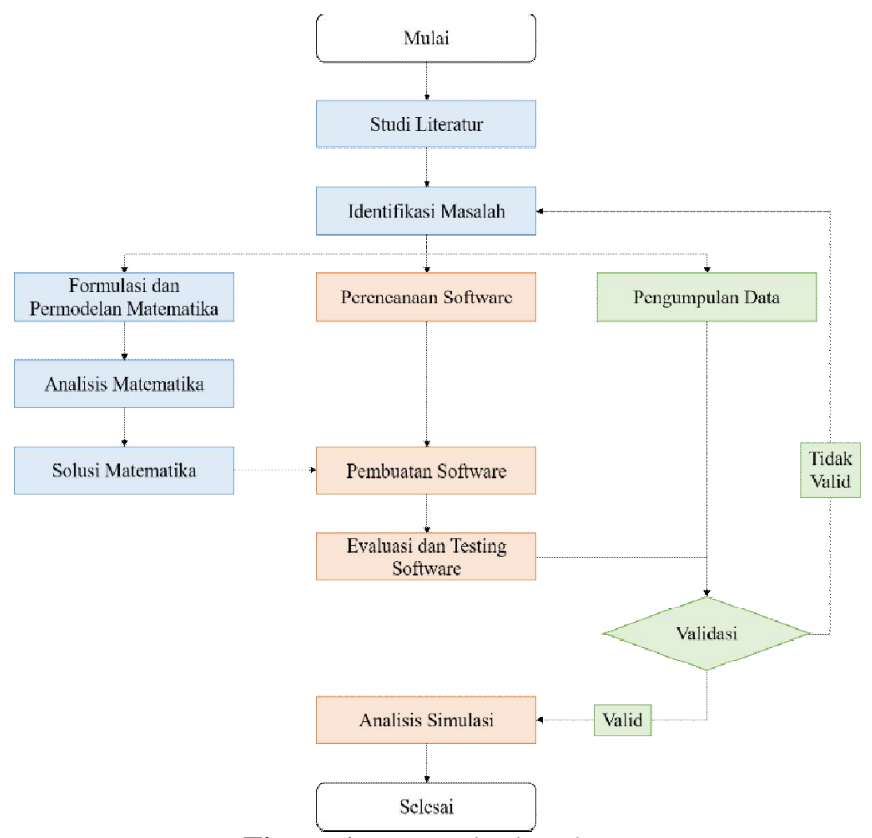

Figure 1: Research Flowchart

\subsection{Literature Study}

Literature study aims to understand better the topics chosen previously. A literature study is done by finding some literature that fits the issue of temperature distribution in the joglo roof space. The source used is the internet in general to search for appropriate journals and several books for the addition of scientific underpinnings that must be completed.

Also not lagging behind the writer looking for some similar research that has been done by other researchers. So that the writer can be more informed about the material and the methods used for related topics

\subsection{Problem Identification}

After conducting a literature study, the next step to be carried out is the identification stage of the problem. At this stage the author will conduct an analysis and identification of issues to be resolved and determine what factors will be there and what factors will be eliminated, the aim is to make a limit on what will be discussed in the research conducted so that the scope of the problem which will be discussed in the study did not become too broad.

\subsection{Mathematical Formulation and Modeling}

The scope of the problems obtained in the previous stage will be made a mathematical formulation that can describe what you want to be examined from these problems. In this stage, the authors will look for a formula suitable for use, which later on the method will be applied to the limits of the problem that has been obtained at the problem identification stage.

Mathematical modeling will be carried out based on the formulations that have been obtained in the previous stages, by changing existing formulations into the form of mathematical modeling based on concepts following the topics discussed to show the real situation of the existing problems. This mathematical modeling will later be used as the core of the program created.

\subsection{Mathematical Analysis}

After completing the stages of mathematical modeling, the writer will analyze existing mathematical modeling to determine the use of methods that have been obtained at the literature study stage and after that implement them. In addition to this, the author will also carry out an analysis to ensure the existing mathematical modeling, whether it can be forwarded to the process of making software or not.

\subsection{Mathematical Solution}

Mathematical solutions can be obtained by completing mathematical modeling using methods that are appropriate from the results of the accurate analysis stages that have been done before, and because the distribution of room temperature is closely related to numerical calculations, the method used by the author is statistical methods. Mathematical settlement can be done by compiling an algorithm for software that can support these calculations.

\subsection{Software Planning}

At this stage, the author will plan the application program algorithm or software to be made. The author will also consider all the functions of the existing software. If it is felt that the role in the current software is not very influential, the writer will delete the feature. The author also follows the design stages following the theories mentioned in the previous chapter.

The author will also make a comparison of programs with similar programs that previously existed. The same program has been created by (Prayoga, 2017) using the python programming language. The following is a comparison of features in the program that will be made with a pre-existing program. 
Raihan Hendraji et al., International Journal of Emerging Trends in Engineering Research, 8(9), September 2020, $5788-5793$

\subsection{Software Making}

Making software will be done with the python programming language. The making will also follow the algorithm and planning that has been made from the previous stage. Without forgetting the beauty aspect of the author also does not forget to make the software look as attractive as possible and as comfortable as possible so that users are not confused about using the software made.

\subsection{Implementasi Model dan Solusi Matematika}

At the implementation stage of mathematical models and solutions, the author will enter all the formulas that have been obtained from the Mathematical Formulation and Modeling process. The mathematical solution that will be used is also in accordance with the results of the previous mathematical formulation and modeling.

\subsection{Evaluation and Testing}

After finishing the software, the writer will evaluate and test the program to simulate the mathematical modeling that has been made. Data obtained from supporting journals will assist in the evaluation and testing process. There will be two types of evaluation processes carried out by the authors, namely:

\subsection{Simulation Analysis}

Stages of simulation analysis are carried out after the evaluation and testing process is completed, and the results of the simulation are valid when the validation process is carried out. At this stage, an analysis of the parameters that affect the research will be conducted to see the effect of these parameters on the results of the study.

\subsection{Data Collection}

In this research, the type of data used is secondary data, so the authors collect data by looking for journals or supporting references that contain data about the distribution of room temperature and data about room temperature comfort in certain areas that will be used in the validation process of software created.

\subsection{Validation}

The validation process is a process carried out to test the truth of the simulation results obtained from the testing and evaluation stages by making comparisons between the data collected from the program with the data from journals that become a reference in conducting research. If the results of the validation are valid or correct following the data from the journal, the study will proceed to the next stage, namely the simulation analysis stage. But if the results of the simulation do not match the desired results or are invalid, then the research will be repeated back to the problem identification stage, and after that will proceed to the next step following the planned methodology flow.

\subsection{Waterfall Model Development Model}

Waterfall model is a software development method that will be used by the author in making software in this study. The process of creating software this time is divided into five, namely Communication, Planning, Modeling, Construction, and Deployment. All these stages will be explained as follows:

1. Communication

In the Communication process, the writer will find out what needs and functions that must exist in the software that will be made under the problems and the existing solutions.

2. Planning

In the Planning process, the author will design software that will be made following the previous procedure. The author also makes the stages of work that must be done so that there is no delay in processing time in this study.

3. Modelling

In the Modeling process, the author will pour the plan or design that has been made into the form of a data flow diagram (Data Flow Diagram) to make it easier to do construction and an understanding of the software made increases. The author will also create mockup interface in this modeling process.

4. Construction

At this Construction stage, the writer will write code for software that has been designed before. The author will use the python programming language for this research. Display interface will also be created in the same style using only a different module that is using TkInter in the python programming language.

5. Deployment

At the Deployment stage, the author will distribute the software that has been made to the community for evaluation by users.

\subsection{Data Flow Diagram}

For modeling in this study, the authors chose to use Data Flow Diagrams to assist in the modeling process. The author will use DFD level 0 and DFD level 1 for modeling software that will be made in this study. Here is a Data Flow Diagram modeling that will help the writer plan and understand the software that will be better prepared.

\subsection{Data Flow Diagram Level 0}

In Figure 3.2, the level 0 diagram of data flow is explained by the writer for the software that will be created in this study. The user will fill in the requirements needed by the program for the simulation. The program will produce a simulation in the form of animation with data in accordance with what has been entered by the user.

\section{RESULT AND DISCUSSION}

In the simulation and discussion of this study, the writer will divide the simulation into three. The distribution will be done based on existing data sources. The first simulation uses data from research results [7], and the second uses data from research results [2]. The third simulation is a comparison of applications with applications of research results (Prayoga, 2017).

In the first two simulations, the author will do a simulation calculation on the test domain in both simulations with two 
Raihan Hendraji et al., International Journal of Emerging Trends in Engineering Research, 8(9), September 2020, 5788 - 5793

different schemes. The first scheme is a separate scheme up to the application of the steady-state equation used as the heat value at time 0 . It is because the heat value obtained from the steady-state equation is stable or not easy to change with time. Joglo-roofed building simulations will use equations (4.10) and (4.41) for assistance at all points that require ghost point schemes under steady-state conditions.

The simulation boundary conditions will be used in existing test domains and have been discretized to obtain test points which will be a representation of the temperature distribution in joglo roofed buildings. The temperature calculation at the test points will be carried out using the gauss-seidel method in equation (4.46) and assisted by comparison (4.47) for the test point conditions that have ghost points. The computer will do the process repeatedly (iteration) until the difference in the value of the new temperature with a temperature value that was previously smaller than the predetermined error standard $(\varepsilon)$. The points that have been obtained will be formed into a contour graph that will show the temperature distribution with the shape of the joglo-roofed building.

After getting the simulation results in a steady-state (the first scheme) simulation will be carried out with the second scheme, namely the finite difference scheme which is applied in the heat equation in an unsteady-state state. The simulation process is done by equations (4.15) and equation (4.45) to do calculations at ghost point points. For discretized test domains, numerical calculations will be performed using equations (4.48) and equations (4.49) at points that require ghost points. The second scheme will be used to find the value of heat in the 1 st to the last time.

Each simulation will be given a direct explanation for the results of the simulation. The following is a simulation and discussion conducted by the author:

Simulation and Discussion 1

In the simulation and discussion of 1 data to be used is research data from [7], only states the value of the outer surface of the roof is $43.5 \square$ according to the measurement results. This study only provides these limits which will be simulated by looking at the temperature of the roof of the joglo building. In the program created by the author, the author cannot affect temperature distribution calculations by only taking part of the roof. Therefore, the author will enter the average value of the calculation results [7] for the temperature of the building floor, the left wall of the building, and the right wall of the building. The temperature entered is equal to $36.5 \square$.

\subsection{Simulation and Discussion 2}

The data that will be used also is data from the results of research belonging to [2] will then be discussed in simulation, and discussion 2 which states the temperature on the roof of the building is $30 \square$, the temperature of the wall left is $25 \square$, right wall temperature is $25 \square$, and building floor temperature is $25 \square$. Following the study, the limits used in determining the width of the building and the height of the building are 6 meters and 7 meters.

\subsection{Simulation and Discussion 3}

For the third simulation, the authors will compare the simulations carried out with the property program (Prayoga,
2017) because the resulting program is similar. (Prayoga, 2017) makes a similar program that can see the temperature distribution in buildings but is limited in three types of roof forms, namely a square roof, triangular roof, and convex roof.

Figure 4.11 shows the comparison between the results of the simulation program belonging (Prayoga, 2017) (contour graph on the left) with the simulation results of the author (contour graph on the right). Simulation is done with the same size between simulations (Prayoga, 2017) with simulations by the author. Based on the observation of the images, the results obtained have been the same in terms of the temperature range to the color gradation in the graph depicting the temperature distribution in the building. In the property program (Prayoga, 2017), you cannot do simulations with the form of a jog roof. The author makes adjustments so that the comparison is carried out following an angle of $45^{\circ}$ so that it becomes the same triangle shape as the program (Prayoga, 2017).

\section{CONCLUSION AND SUGGESTION}

\subsection{Conclusion}

Based on the research that has been done, the following results are obtained:

1. Unsteady-State heat equation which is solved numerically through different schemes up to the ghost point method through a quadratic extrapolation approach, can solve the heat equation modeling on buildings with joglo-shaped roofs.

2. The program is based on existing mathematical modeling and is done using the python programming language. The application of this research has been created by inputting dynamic data (the user can create the desired shape of the building by entering the form into the available grid) and determining the initial temperature of the building roof, initial temperature of the right wall of the building, initial temperature of the left wall of the building, temperature the beginning of the building floor, as well as the time to be tested.

3. The program is created using the python programming language. With Flat File Database, the calculation results of simulation data entered by users in the form of Array List stored in a file-based database. The file can be called in the program to open the simulation history that has been done before.

4. The value of the temperature distribution in the jogloroofed building produced from the simulation has represented the actual conditions. Proven valid from a comparison of data with previous research. Also, the simulation results show that the temperature distribution is affected by time. The longer the running time, the more even the temperature values in the joglo roof building. In conclusion, again that this program can also be used as a reference for users who will build joglo-roofed buildings.

5. A roof that can be said to be a joglo roof is a pair of sides that has two different tilt angles and has a pair on the other side that reflects. The angle in the meeting of two roofs on the same side must be greater than $180^{\circ}$. 
Raihan Hendraji et al., International Journal of Emerging Trends in Engineering Research, 8(9), September 2020,5788 - 5793

From the results of experiments conducted in this study, the geometry of the joglo roof is the most ideal way to reduce heat in the joglo-roofed building.

Based on the results of these simulations, the writer can conclude that this research has been successful.

\subsection{Suggestion}

Based on the conclusions that have been made, suggestions from the authors for the further development of the modeling program are as follows:

1. Development of the shape of the roof that can be simulated, not only the form of the joglo roof can be added to other types of roofing such as a pyramid roof or frog roof.

2. Variations in the form of the joglo roof can be added to other joglo roof shapes such as the joglowantahapitan and joglomangkurat which have three slanted sides on the roof.

3. In this study, the quadratic extrapolation approach is used to solve the ghost point method, for future research development, it is better to use another extrapolation approach.

4. In further research, development can be done by adding the assumption that the house building under study is not empty so that there is a source of heat in the object being tested

Future studies can add a variable of heat propagation to the roofing material used in joglo roofed buildings.

\section{REFERENCES}

[1] G. Lippsmeier, "Tropenbau Building in the Tropics," Bangunan Trop., 1994.

[2] T. Sirteerakul, S., Chamnan, W., \& Siriteerakul, "Temperature Distribution in Three Model Houses with Different Roof Geometries," J. Autom. Control Eng., vol. 2, no. 1, pp. 71-74, 2014.

[3] A. D. Prayoga, Analisis Suhu Unsteady-State Berdasarkan Geometri Atap Menggunakan Quadratic Extrapolation Ghost Points Berbasis Python. Jakarta Barat: Universitas Bina Nusantara, 2018.

[4] A. Albaiz, "High-Order Finite-Difference Discretization for SteadyState Convention-Diffusion Equation on Arbitrary Domain," pp. 1-13, 2014.

[5] J. Kiusalaas, Numerical Methods in Engineering with Python 3. New York: Cambridge University Press, 2010.

[6] J. Kiusalaas, Numerical Methods in Engineering with Python 3. New York: Cambridge University Press, 2013.

[7] R. Purwanto, L., Hermawan, Sanjaya, "Pengaruh Bentuk Atap Bangunan Tradisional di Jawa Tengah untuk Peningkatan Kenyamanan Termal Bangunan,' Dimens. Tek. Arsit., vol. 34, no. 2, pp. 154-160, 2006. 